\title{
Technical letters (capital) writing: A new concept
}

\begin{abstract}
The present work investigated the current state of letter writing methods in the emerging field of engineering education and identifies difficulties experienced by scholars and educators who have been involved in teaching the subject Engineering Graphics. Most of the students are not able to follow the methods that are used to write letters since technical lettering being written in graphs by various authors of engineering drawing do not follow a specific procedure, and no standard practice is maintained so far. After thorough discussions with faculty members and students, it was identified that the difficulties with lettering were: $d / h$ ratio and, curvatures. The ratio of height versus width of the capital letters varies in different ways which appear to produce a sense of confusion among engineering students and practitioners. The curvatures of various letters are not standard and are very difficult to remember. This took our interest for investigation, and a new method of lettering was developed and proposed, which is very simple, easy to remember and provides a standard method to be followed.
\end{abstract}

\section{KEY WORDS}

Capital letters, $\mathrm{d} / \mathrm{h}$ ratio, Gothic letters

\author{
Murari Prasad ${ }^{1}$ (i), \\ Ravi Shankar Prasad ${ }^{2}$ (1), \\ Deepika Mishra² (1), \\ Piyush Gaur ${ }^{3}$ (D) \\ ${ }^{1}$ Department of Electrical \\ Engineering, Aryabhatt Institute \\ of Management \& Technology, \\ Dhanbad, India \\ ${ }^{2}$ Department of Mechanical \\ Engineering, Raj Kumar Goel \\ Institute of Technology, \\ Ghaziabad, India. \\ ${ }^{3}$ Department of Mechanical \\ Engineering, IIT Delhi, India.
}

Corresponding author: Ravi Shankar Prasad e-mail:ravp077@gmail.com

First recieved: 26.05.2017. Accepted: 27.04.2018.

\section{Introduction}

Since long engineering drawing has become an essential part of any engineering work. Engineering drawing is used as a language through which an engineer can communicate his idea to other engineers. For any important construction work and manufacturing, decisions are made over the engineering drawings made for the same. In engineering, drawing letterings are used to write descriptions of parts and their dimensions in the English language since the English language is globally used as a link language. Most of the countries follow the English language as a medium of teaching, conversation and communication. Engineering Drawing is defined as the language of engineering, and English letters are universally used for identification and enumeration of drawings.
As such Technical Lettering of English Alphabets plays a crucial role in engineering drawing which is evident by the facts of introducing this as an essential part of course-curriculum at the level of B. Tech Programme, Diploma in engineering and vocational training programs for technicians. While teaching the subject, Engineering Drawing, the necessity of developing a standard method for writing Capital Gothic Letters was deeply felt which led to the development of the new method that not only simplifies the drawing procedure but is most easy to remember by practising engineers and beginners as well. The details of the same are discussed below. 


\section{Literature review}

In the post-globalization era, standards (like ASTM, ISO, etc) are universally adopted and engineering drawing is not an exception to it. The existing methods followed by engineering community in writing capital Gothic Letters lack in simplicity, and standard methods are not followed while drafting the letters on graphs. This leads to difficult practices of writing Gothic capital letters and they are not easy to remember and follow.

It was observed that for freehand lettering guidelines are used to ensure consistency in the size of the letter characters. In the case of lettering consists of capital letters, the existing practice is to draw the letters between cap line and base line (Integrated Publishing, 2008; Zurbuch, 2005). In a book authored Bhatt, (1959) in the year 1959, it was found that the ratio of height to width varies, but in most of the letters, it is 6:5. Later in his revised edition, (Bhatt \& Panchal, 2008) talked about gothic letters, and it was found that the stems of single-stroke letters if given more thickness, it is referred to as gothic letters. These are mostly used for main titles of ink-drawings. The outlines of the letters are first drawn with the aid of instruments and then filled-in with colour ink. The thickness of its stem may vary from $1 / 5$ to $1 / 10$ of the height of the letters as described in IS 9609-1990 (Bhatt \& Panchal, 2008).

In a lecture note of Wuttet Taffesse at Haramaya University, it was observed that in accordance to have legible and accurate letter styles, a set of letters are categorized and has been arranged in group (Taffesse \& Kassa 2005). As per BIS code SP46-1988 (Convention, 1988), there is a process of writing Gothic capital letters, which provides $d / h$ ratio as $1 / 14$ and $1 / 10$. Different $\mathrm{d} / \mathrm{h}$ ratio presents a flexible and uncertain picture. Thus it is observed that the above procedure is very difficult to remember and not easy to follow. The various methods under reference present the processes which differ from each other at certain points which may create a sense of confusion among various users.

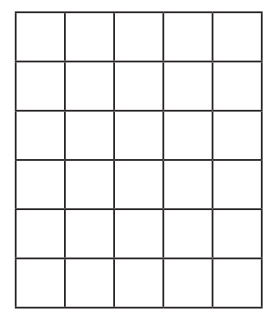

» Figure 1: Graphical space of $35 \mathrm{~mm}$ x $25 \mathrm{~mm}$ for letter drawing

\section{Limitation of existing method}

The various methods used in the existing system leads to a state of confusion among engineering professionals and students for the following reasons: (i) letters are written in various graphic proportions like $6 \times 4,6 \times 6,8 \times 8$, (ratio of height and width) etc, (ii) they are also written at various inclinations as per the liking of individual practitioners, (iii) different curvatures are used for forming different letters and (iv) $d / h$ ratio is not uniform.

\section{Methodology}

Many letters of the alphabets have curvatures which vary from one to other. In the new method, as illustrated below, the curvatures of all such letters are standardized and follow the same procedure of curve formation. There is a need to draw a graphical space of $35 \mathrm{~mm} \times 25 \mathrm{~mm}$ using a square of the $5 \mathrm{~mm}$ side as shown in Figure 1. This graphical space can be used for each alphabetical letters except for I and W. The same graphical space is also used for writing numerical letters from 0 to 9 except for 1 .

The letter $W$ will have a size $7 \times 7(35 \mathrm{~mm} \times 35 \mathrm{~mm})$, I will be of $7 \times 1(35 \mathrm{~mm} \times 5 \mathrm{~mm})$ size. The numerical letter 1 has a graphical size of $7 \times 1(35 \mathrm{~mm} \times 5 \mathrm{~mm})$ with a small extension at the top left to distinguish it from letter I. The gap between two alphabetic letters, or numerical letters were kept as $5 \mathrm{~mm}$, and between two consecutive rows, the gap maintained was $10 \mathrm{~mm}$. All outer curvatures of curved letters are drawn as a quarter circle with a radius of one graph (here one graph refers to a square of $5 \mathrm{~mm}$ side) and the inner curvatures was kept as a quarter circle of radius half of that of the outer one, i.e. $2.5 \mathrm{~mm}$. The dimensional value of the outer and inner curvature drawn is as shown in Figure 2. Letter $Q$ has a tapered extension of one graph beyond its bottom in the centre. For writing numerical letters, the curvatures follow the same process as adopted for the alphabetic letters. All letters have vertical configuration only. For making any change in the size of letters the only change in the size of the square is to be incorporated. Graphical presentation of the new standard concept is illustrated below in Figure 3, Figure 4, Figure 5 and Figure 6 where the writing of letters A, C, Q and $D$ are graphically drawn. Processes followed to draw each letter, all together constitute a new standard.

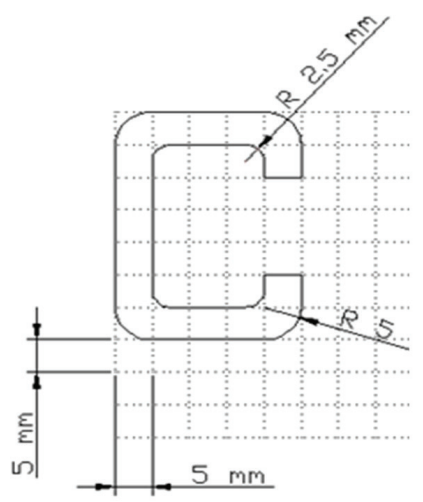

» Figure 2: Dimensional values of curves and unit graph 


\section{Results and Discussions}

Let the configuration of the letter $A$ as shown in Figure 3 be analysed. This letter has been drawn at a definite pattern by joining the extreme bottom squares diagonally to top centre square of the area assigned to this letter. The cross bar of the letter has been obtained by joining the two diagonal arms just at the second square from the bottom. The result is a very impressive appearance of the letter than the previous ones.

When the letter $\mathrm{C}$ was taken for discussion, we observe that all corners of the letter have standard and specified contours as is evident from the illustrated Figure 4.

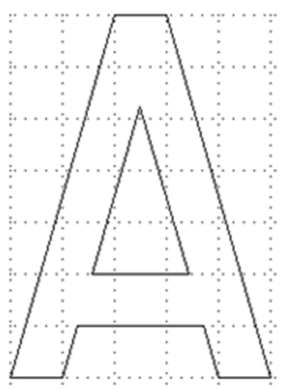

» Figure 3: Letter ' $A$ '

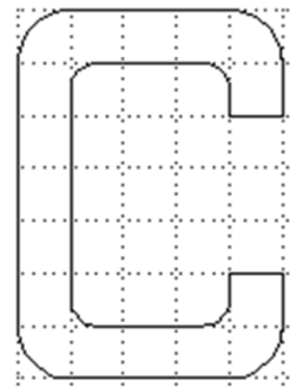

» Figure 4: Letter ' $C$ '
It was observed that as the right side gap of letter $\mathrm{C}$ is filled up, it gets converted into letter $\mathrm{O}$ and with a small addition, it was easily converted to $Q$ as is evident from the illustration of Figure 5.

If the left top and bottom corners of letter $O$ are just made at right angles by removing its curvatures, the letter D is formed as illustrated in Figure 6. Similar methods were used to write other letters.
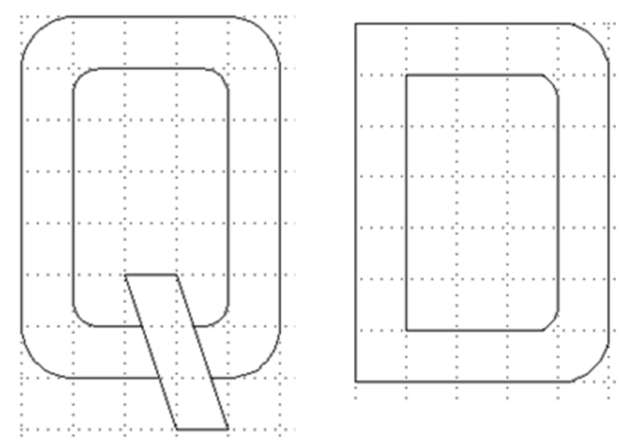

» Figure 5: Letter ' $Q$ '

» Figure 6: Letter ' $D$ '

\section{Conclusions}

It has been observed that all concurrent authors of Engineering Drawing, more or less, have just copied the system followed by their ancestors on the topic. The authors predict that the new methodology discussed above for technical lettering will open a new era on the topic worldwide if accepted and followed. One of the authors have had experience of being taught the topic by his teacher almost 50 years back, and the same pattern is still followed. No one has, in fact, thought of suggesting any new concept on the topic since its inception in the history of technical teaching. The authors are very optimistic that this novel idea will be gladly accepted by present and future practitioners, technical teachers, engineers, students and the concerned authorities responsible for the development of technical education worldwide.

The existing method doesn't follow any specified curvature where as the new method follow. In new method each curve can be measured and dimensioned. In the earlier methods (Calligraphy Skills, 2018) the curve generated depends on the skill sets of the person or draftsman.

The curvature that varies from alphabet to alphabet or depends on individual's skill sets may puzzle draftsman and leads to a hectic and cumbersome process. This problem is taken care by new method proposed and even software packages like AUTOCAD can be used to write gothic letters.

Its presentation on AUTOCAD will have far simpler programming than existing system. The standardization of curvatures gives a better look and learning becomes easier.

\section{References}

Bhatt, N. D. (1959) Elementary engineering drawing. [Plane and solid geometry] Part 1. Anand, Charotar Book Stall.

Bhatt, N. D. \& Panchal, V. M. (2008) Elementary engineering drawing. [Plane and solid geometry]. Anand, Charotar Publishing House.

Convention, B. I. S. (1988). ISO and BIS Convention or Code. Available from: https://www.google. $\mathrm{com} /$ url? sa $=t \& r c t=j \& q=\&$ esrc=s\&source=web\&c$\mathrm{d}=1 \&$ ved $=0$ ahUKEwi1xfHV8sPbAhWpiaYKHU2qDBMQFggoMAA\&url=https\%3A\%2F\%2Fwww. ikbooks.com\%2Fhome\%2Fsamplechapter\%3Ffilename\%3D151_Sample-Chapter.pdf\&usg=AOvVaw2Dv0qPT5oU7PW6r1ecWkAO [Accessed 13th October 2017].

Calligraphy Skills (2018) More gothic writing: CAPITAL gothic letters A-Z. Available from: https:// www.calligraphy-skills.com/gothic-writing. html [Accessed 13th October 2017].

Integrated Publishing (2008) Freehand lettering. Available from: http://www.tpub.com/engbas/327.htm [Accessed 13th October 2017].

Taffesse, W \& Kassa, L. (2005) Engineering Drawing. 65, 1-6. Haramaya University. Available from: https:// www.cartercenter.org/resources/pdfs/health/ephti/ 
library/lecture_notes/env_health_science_students/ engineeringdrawing.pdf [Accessed 13th October 2017].

Zurbuch (2005) Technical Lettering. Kent State University. Available from: http://www.personal.kent.edu/ $r$ bavis/lettering.htm [Accessed 13th October 2017].

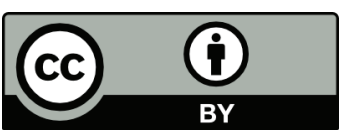

(C) 2018 Authors. Published by the University of Novi Sad, Faculty of Technical Sciences, Department of Graphic Engineering and Design. This article is an open access article distributed under the terms and conditions of the Creative Commons Attribution license 3.0 Serbia (http://creativecommons.org/licenses/by/3.0/rs/). 